Fedor, E. J., Lee, S. H., and Fisher, B. (1959). Surg. Forum,

10, 875.' 1958). Clin. Chem., 4, 62.

Findlay, J., Levvy, G. A., and Marsh, C. A. (1958). Biochem. J., 69, 467.

Fowler, R., and West, C. D. (1960). Transplant. Bull., 26, 133 - (1961). Aust. J. exp. Biol. med. Sci., 39, 537.

Hairston, P., and Muller, W. H. (1961). Surg. Forum, 12, 206.

Janigan, D.' T., and Santamaria, A. (1961). Amer. J. Path., 39, 175 .

Levvy, G. A., and Marsh, C. A. (1959). Advanc. Carbohyd. Chem., 14, 381

Lowry, O.. H., Rosebrough, N. J., Farr, A. L., and Randall, R. J. (1951). J. biol. Chem., 193, 265.

Novikoff, A. B. (1959). J. biophys. biochem. Cytol., 6, 136.

Pearse, A. G. E. (1960). Histochemistry, Theoretical and Applied, 2nd ed. Churchill, London.

Porter, K. A., and Calne, R. Y. (1960). Transplant. Bull., 26, 458. Rondie, C. J. M., and Morgan, W. T. J. (1955). Biochem. J.,

Tyler, H. M., Lister Cheese, I. A. F., Struthers, N. W., and Dempster, W. J. (1962). Lancet, 2, 432

Umbreit, W.' W., Burris, R. H., and Stauffer, J. F. (1957) Manometric Techniques. Burgess Publishing Co., Minneapolis.

Vannotti, A. (1961). Ciba Foundation Symposium, Biological Activity of the Leucocyte, p. 79. Churchill, London.

Volkin, E., and Cohn, W. E. (1954). Meth. biochem. Anal., 1, 287.

\section{NATURAL HISTORY OF THYROID CARCINOMA}

\section{A STUDY OF 152 TREATED PATIENTS}

BY

\section{J. I. BURN,* M.B., F.R.C.S.}

Senior Surgical Registrar, Postgraduate Medical School, Hammersmith Hospital, London

\section{AND}

\section{SELWYN F. TAYLOR, D.M., M.Ch., F.R.C.S.}

Surgeon, King's College Hospital, and Postgraduate Medical School, Hammersmith Hospital, London

In order to try to piece together the natural history of thyroid carcinoma we have studied 152 patients with proved carcinoma of the thyroid who attended Hammersmith Hospital and King's College Hospital during the decade 1950-9. Since 62 of the patients were referred for radiotherapy, having had a biopsy or some kind of surgical excision elsewhere, this represents a highly selected group, and the incidence of carcinoma of the thyroid probably does not reflect the incidence of the disease in the general population. About one-third of these patients were included in a clinicopathological study reported by Alhadeff et al. (1956).

Carcinoma of the thyroid is not common, but it is of considerable interest and presents an unusual pattern of behaviour in that the younger the patient affected the better is the chance of survival. Although rare, it is important to diagnose the disease correctly as a variety of methods of treatment is now available.

\section{Classification}

For all practical purposes thyroid carcinoma can be considered as two separate diseases, so great are the differences between the anaplastic (undifferentiated) carcinoma on the one hand and the differentiated variety with its papillary and follicular patterns on the other. This fundamental observation was originally stressed by Dunhill (1931), and again more recently by

*Now at Department of Surgery, Rosswell Park Memorial Institute, Buffalo, New York State, U.S.A.
Crile et al. (1948), Crile and Hazard (1953), and Crile (1957). It is convenient to subdivide the differentiated thyroid carcinomas into papillary and follicular after the manner of Warren and Meissner (1953), although this is to some extent an arbitrary division because it is usual to find papillary elements in most follicular carcinomas and follicular elements in the papillary ones. However, it is still possible to apply the term papillary or follicular according to which pattern has predominated in the number of fields examined under the microscope (Alhadeff et al., 1956). Approximately two-fifths of our patients presented with the anaplastic type of carcinoma and the rest with differentiated lesions (Table I) ; this is a larger proportion of anaplastic lesions than in most published series (Table II), and is probably due to the fact that anaplastic tumours are especially suitable for radiotherapy and such patients were accordingly referred to the Medical Research Council's Radiotherapeutic Unit at Hammersmith Hospital. The size of these groups of patients allows comparison to be made between the behaviour of the different types of carcinoma.

It is not intended here to extend the arguments on histological interpretation of thyroid carcinoma, except to say that all attempts at classifying a disease must at times be somewhat arbitrary. In the case of thyroid carcinoma these difficulties have been exaggerated in the past because too much reliance has been placed on the histological appearances without reference to the general clinical picture, spread of the disease, and subsequent history of the patient. In addition due regard must be given to the response to treatment, the laboratory findings, and other investigations. A better appreciation of the natural history of the disease reselves many of the difficulties of classifying thyroid carcinoma.

\begin{tabular}{|c|c|c|c|c|}
\hline Type & Female & \multicolumn{2}{|c|}{ Male } & \multirow[b]{2}{*}{$\begin{array}{l}43\} 86(57 \%) \\
43\}(43 \%) \\
66(43 \%)\end{array}$} \\
\hline $\begin{array}{l}\text { Follicular .. } \\
\text { Papillary } . . \\
\text { Anaplastic }\end{array}$ & $\begin{array}{l}33 \\
29 \\
47\end{array}$ & \multicolumn{2}{|c|}{$\begin{array}{l}10 \\
14 \\
19\end{array}$} & \\
\hline Total & 109 & \multicolumn{2}{|c|}{43} & \\
\hline \multicolumn{5}{|c|}{ Female: male ratio $=2 \cdot 5: 1$} \\
\hline \multicolumn{5}{|c|}{$\begin{array}{l}\text { TABLE II.-Published Incidence of Histological Types of } \\
\text { Carcinoma }\end{array}$} \\
\hline $\begin{array}{l}\text { Histological } \\
\text { Type }\end{array}$ & $\begin{array}{l}\text { Kilpatrick } \\
\text { et al. } \\
\text { (1957) }\end{array}$ & $\begin{array}{c}\text { Franz and } \\
\text { Yannopoulos } \\
\text { (1961) }\end{array}$ & $\begin{array}{c}\text { Lindsay } \\
\text { (1960) }\end{array}$ & $\begin{array}{l}\text { Woolner } \\
\text { et al. } \\
(1960)\end{array}$ \\
\hline $\begin{array}{l}\text { Follicular } \\
\text { Papillary } \\
\text { Anaplastic } \\
\text { Miscellaneous }\end{array}$ & $\begin{array}{c}45 \% \\
23 \% \\
30 \% \\
2 \% \\
\text { (epidermoid } \\
\text { carcinoma) }\end{array}$ & \begin{tabular}{c|}
$24 \%$ \\
$58 \%$ \\
$11 \%$ \\
$7 \%$ \\
(solid, well \\
differentiated)
\end{tabular} & $\begin{array}{l}30 \% \\
\mathbf{9 1 \%}\end{array}$ & $\begin{array}{l}14 \% \\
60 \% \\
13 \% \\
10 \% \\
\text { (solid) }\end{array}$ \\
\hline
\end{tabular}

Thirteen unusual malignant lesions of the thyroid were seen during this 10-year period. Five of these were squamous carcinomas or tumours showing squamous metaplasia, seven were considered to be sarcomas, and one was a metastasis from carcinoma of the bronchus. It is possible that some of the so-called sarcomas were highly anaplastic carcinomas. There was also one example of "struma reticulosa" which conformed to the histological appearance and subsequent behaviour of some of the cases first described under this name by Brewer and Orr (1953). This patient, a woman aged 49, presented with a six-month history of swelling in the neck. Excision of the entire right lobe of the thyroid was performed, and it was reported as an anaplastic 
carcinoma. She received a course of radiotherapy to the neck and her subsequent progress has been uneventful ; she remains well after five years. During this period the histology has been reviewed and the diagnosis changed from anaplastic carcinoma to that of struma reticulosa.

\section{Aetiology}

Role of Hormones.-A vast amount of work has been carried out in recent years on the production of malignant lesions of the thyroid gland in animals, especially rats. Much of this work has stemmed from the fact that giving an animal thiouracil blocks the synthesis of thyroxine in the gland, and this in turn leads to excessive production of thyrotrophin (T.S.H.) from the anterior pituitary, with resulting hyperplasia of the thyroid gland. Money and Rawson (1950) produced a number of diverse types of tumour in rats on long-term thiouracil, but found it difficult to justify a diagnosis of malignancy on the sole basis of histological examination. Bielschowsky (1944) showed that the addition of a carcinogen such as 2-acetyl-amino-fluorene (A.A.F.) when the thyroid was under the stimulus of T.S.H. led to the induction of a high proportion of carcinomas among these hyperplastic thyroid glands.

It might be anticipated that in areas of endemic goitre, where the population as a whole is subjected to increased thyrotrophic activity, the incidence of thyroid carcinoma would be higher. There is considerable evidence in support of this, dating from Wegelin (1928), but it is always difficult to obtain statistics from one country and compare them with those from another (Taylor and Goolden, 1959), so that some of these figures must still be viewed with healthy scepticism. Certainly, however, a reduction in the incidence of endemic iodinedeficiency goitre due to the introduction of iodized salt has been shown to be accompanied by a fall in the incidence of thyroid cancer (Wynder, 1952), although not all reports agree with this (Walthard, 1961).

Relationship to Previous Goitre.-We have attempted to assess how many of the carcinomas reported here occurred in patients who previously were known to have enlargement of the thyroid gland. The empirical figure of 10 years' thyroid enlargement previous to the diagnosis of malignancy was adopted, and $17 \%$ of patients who developed an anaplastic carcinoma gave such a history, while among the differentiated group it was $22 \%$ (Table III). It will never be possible to say how many of these thyroid enlargements were malignant from the start, or to estimate with any certainty at what time a malignant change took place in a thyroid swelling previously benign. Certainly it seems likely that a number of the very well differentiated lesions had the same histology from the time that they were first noticed in the neck. Table III also shows that, whereas $56 \%$ of patients with a well-differentiated lesion gave a history of a swelling in the neck for over 12 months, only $26 \%$ of patients with an anaplastic lesion gave such a history. In brief, it would seem that differentiated carcinoma tends to occur where and when simple goitre is common and tends to run a protracted course. Anaplastic thyroid

TABLE III.-History of Previous Thyroid Swelling

\begin{tabular}{|c|c|c|c|c|}
\hline $\begin{array}{c}\text { Thyroid } \\
\text { Swelling } \\
\text { Apparent for }\end{array}$ & Follicular & Papillary & $\begin{array}{c}\text { Total } \\
\text { Differen- } \\
\text { tiated }\end{array}$ & Anaplastic \\
\hline 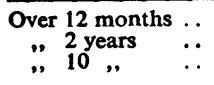 & $\begin{array}{l}61 \% \\
53 \% \% \\
30 \%\end{array}$ & $\begin{array}{l}51 \% \\
33 \% \\
14 \%\end{array}$ & $\begin{array}{l}56 \% \\
43 \% \\
22 \%\end{array}$ & $\begin{array}{l}26 \% \\
20 \% \\
17 \%\end{array}$ \\
\hline
\end{tabular}

carcinoma appears to have no close correlation with simple goitre and runs a rapid course.

Immunological Factors.-Mention must be made of the suggestion that Hashimoto's disease may be a premalignant process. Lindsay (1960) found an incidence of $20 \%$ thyroid carcinoma in a group of patients with Hashimoto's disease, although this has not been our experience. Since autoimmunity is the accepted aetiological factor in Hashimoto's thyroiditis, it raises the question of the possible importance of immunological factors in the development of carcinoma. There appears to be no good evidence to support this at present.

Role of Radiation.-There are reports that children who have been subjected to irradiation of the neck or thorax in infancy, even with small doses, later develop thyroid carcinoma (Simpson and Hempelmann, 1957; Winship and Rosvoll, 1961). Doniach (1957) has shown that there is an increased incidence of thyroid cancer in rats receiving thiouracil subjected to internal or external thyroid irradiation. In the present series of patients, four gave a history of previous irradiation to the neck; three of these had been irradiated for thyrotoxicosis 18,28 , and 30 years before the diagnosis of carcinoma was made. In the fourth case irradiation was given after excision of an unspecified tumour 11 years previously.

Doniach (1958) formulated an attractive theory to explain this form of carcinogenesis. He postulated that two factors are necessary to produce a malignant change in the thyroid gland. The first is a non-specific stimulus to growth which is provided by T.S.H. from the anterior pituitary; the second, and the one which appears to trigger off a malignant change in the growing cells, is ionizing radiation in the form of small doses of $x$ rays or radioactive iodine, or a chemical carcinogen such as A.A.F. Since it is during the foetal and prepubertal period that the thyroid is mainly subjected to a growth stimulus, this would explain why ionizing radiation to the gland is more likely to lead to a malignant change in babies and children than in adults.

\section{Incidence}

Attempts have been made in recent years to determine the natural incidence of thyroid carcinoma in various centres of the world, but for a variety of reasons such statistics are not usually suitable for comparison. For example, Vanderlaan (1947) used the necropsy records of a large hospital and found an infinitesimal percentage of thyroid carcinomas responsible for death (5 out of 18,668 patients), probably because many of the patients died at home and not in hospital. Willis (1961), in Belfast, found 15 out of 15,100 necropsies - that is, $0.1 \%$-as did Wilson (1921). Sokal (1953) collected records from many centres and used both necropsy and mortality tables; he arrived at what is probably the more accurate figure of 25 patients per year with thyroid cancer in a community of $1,000,000$ people. Unfortunately the statistics available rarely explained which variety of carcinoma predominated, and there is probably a fundamental difference between differentiated and anaplastic thyroid tumours.

\section{Sex Incidence}

Carcinoma of the thyroid is predominantly a disease of females, but the sex ratio is not so marked as in simple and toxic goitre. The overall incidence in this series shows a preponderance of females over males of 
2.5 to 1 , which is a higher ratio than that mentioned in most other reported series ; for example, that of Pemberton (1938) of 1.7 to 1 . In our hospitals the incidence of simple goitre is seven or eight times higher in women than in men, and toxic goitre is also much more common in the female.

In a previous publication (Alhadeff et al., 1956) we tried to break down these figures even further into the various age-groups and show when the different types of thyroid carcinoma were most likely to be encountered. When this is done with the present series the anaplastic carcinoma is typically a disease of late middle age, reaching a peak in its incidence in the seventh decade both in males and in females (Fig. 1). The age incidence of differentiated thyroid carcinoma is much lower, with a peak occurring in the fourth decade (Fig. 2).

If the papillary and follicular lesions in our series are regarded separately there appears to be a special susceptibility of the female to follicular carcinoma in later life. It must be remembered, however, that many of these patients may have harboured a swelling in the neck for a long time before seeking medical advice, and

FEMALES

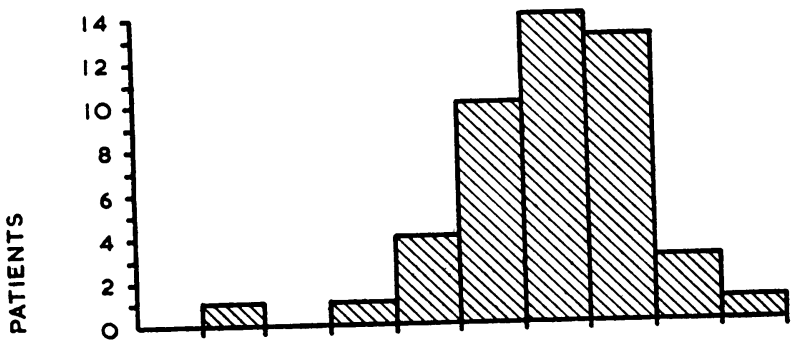

ü

$\dot{0}$

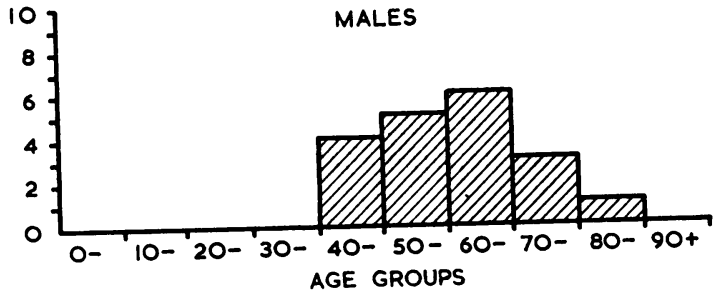

Fig. 1.-Age incidence of anaplastic carcinoma.

FEMALES

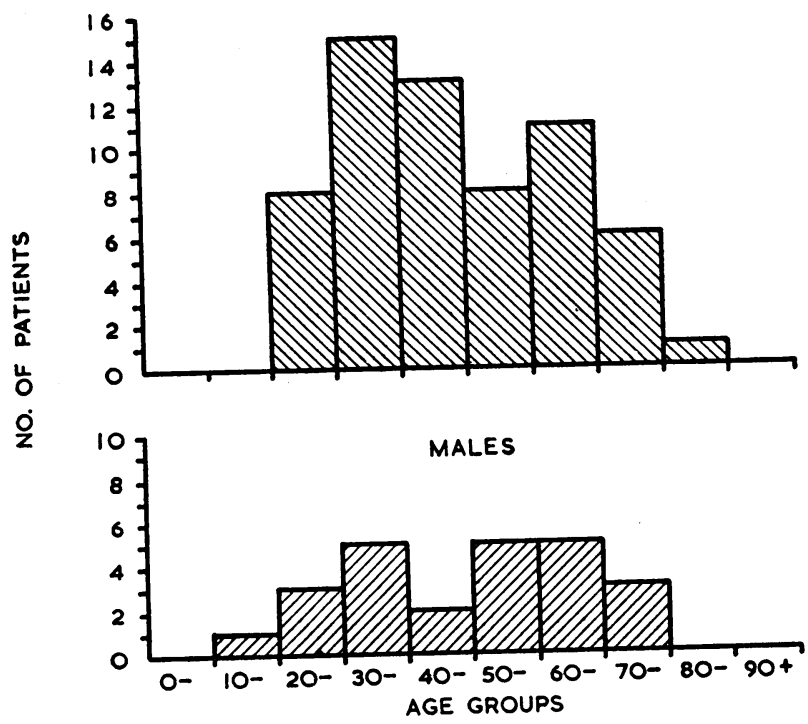

Fig. 2.-Age incidence of differentiated carcinoma. this adds to the difficulties of assessing accurately the age of onset of the disease.

\section{Clinical Presentation}

Most patients with carcinoma of the thyroid report to their doctors in the first place because of the presence of a mass in the neck. In the group of patients with well-differentiated carcinomas no fewer than 77 out of 86 presented with a swelling in the neck, but this swelling was often a discrete nodule rather than a bulky goitre. Of the 66 patients with anaplastic carcinoma, 62 also had a thyroid swelling when first seen, but in 32 of these it was the presence of distressing pressure symptoms which led them to seek advice.

Thus it becomes evident that the two pathological types of thyroid carcinoma present with an essentially different clinical picture. In addition, the differentiated tumours have much less urgent symptoms and often follow a protracted course even when distant metastases are present. In contrast to them, the patients with anaplastic carcinoma almost always develop distressing signs within a comparatively short time due to pressure on the structures in the neck.

\section{Differentiated Carcinoma}

The smaller goitres in the differentiated group were rarely associated with pressure symptoms, and evidence of local spread was seen in only eight. Lymph-node involvement was seen in 11 follicular and 15 papillary lesions ; pulmonary and skeletal metastases were found associated with 18 follicular but only 6 papillary growths (Table IV). Occasionally a patient with a follicular carcinoma of the thyroid presented with symptoms referable to distant metastases, and seven patients gave a history of lower-limb pain related to spinal or pelvic deposits.

The natural history of these tumours may extend over many years, and instances have been recorded of patients with known papillary or follicular carcinoma of the thyroid who have remained in good health for a long time without treatment. In others, long survival has been associated with treatment consisting solely of the administration of thyroid hormone (Dunhill, 1937 ; Balme, 1954 ; Crile, 1957). However, the mortality rate is by no means negligible, and 20 of our patients have already died (Table V), although in one case death was due to an unrelated cerebral haemorrhage.

\begin{tabular}{|c|c|c|c|c|}
\hline Site & $\begin{array}{c}\text { Follicular } \\
\text { (43) }\end{array}$ & $\begin{array}{c}\text { Papillary } \\
\text { (43) }\end{array}$ & $\begin{array}{c}\text { Total } \\
\text { Differen- } \\
\text { tiated } \\
(86)\end{array}$ & $\begin{array}{c}\text { Anaplastic } \\
(66)\end{array}$ \\
\hline $\begin{array}{lr}\text { Direct spread } & \ldots \\
\text { Local lymph nodes } \\
\text { Pulmonary } \\
\text { Skeletal .. }\end{array}$ & $\begin{array}{r}2 \\
11 \\
8 \\
10\end{array}$ & $\begin{array}{r}6 \\
15 \\
2 \\
4\end{array}$ & $\begin{array}{r}8 \\
26 \\
10 \\
14\end{array}$ & $\begin{array}{l}46 \\
18 \\
16 \\
12\end{array}$ \\
\hline
\end{tabular}

TABle V.-Progress of Patients up to January, 1961

\begin{tabular}{|c|c|c|c|c|}
\hline Type & & Alive & Dead & Not Known \\
\hline $\begin{array}{ll}\text { Total differentiated } \\
\text { Follicular } & . \\
\text { Papillary } & \\
\text { Anaplastic } & . .\end{array}$ & $\begin{array}{l}. . \\
\because \\
. \\
\end{array}$ & $\begin{array}{r}51 \\
25 \\
26 \\
6\end{array}$ & $\begin{array}{r}20 \\
12 \\
8 \\
45\end{array}$ & $\begin{array}{r}15 \\
6 \\
9 \\
15\end{array}$ \\
\hline \begin{tabular}{|l|} 
Total \\
\end{tabular} & & $38 \%$ & $43 \%$ & $19 \%$ \\
\hline
\end{tabular}

The large oroup of patients whose fate is not known is due to the fact that The larce group of patients whos hospitals after comnleting a course of many returned to the care 15 in the anaplastic group had known distan metheresed dead. 
Of the 51 known survivors, only 12 were over the age of 50 when they first attended. Evidence of distant spread was present in only two patients when they were first seen, although local lymph-node involvement was common. Some have required repeated local excisions of affected lymph nodes ; block dissection of the neck has been used rarely to deal with such nodes. Their anatomical distribution-for example, in the tracheooesophageal groove and upper mediastinum-is not helped by such a surgical approach.

The tendency towards distant blood-borne spread by the follicular tumours and near-by lymphatic spread by the papillary tumours may account for the better prognosis of the latter. The final impression is that tumours of pure papillary structure offer the best prognosis; it should be noted in Table $\mathrm{V}$ that the predominant histological appearance is used to denote whether a tumour is regarded as papillary or follicular, and the pure papillary lesions are not grouped separately.

\section{Anaplastic Carcinoma}

Symptonis due to pressure were common in this group, the goitres were invariably bulky, and local spread was a regular feature. Local pain was an uncommon symptom, but four patients complained of pain referred to the ear. The presence of involved cervical nodes was usually associated with widespread local tumour invasion, thus differing from the isolated discrete malignant nodes seen with differentiated carcinoma of the thyroid. Distant metastases were common, but in only one patient did a secondary cause present symptoms-namely, pain due to a pathological fracture of the humerus. The rapid growth of the primary tumour usually gave rise to local symptoms before distant metastases became evident. The natural history of a disease is usually difficult to assess because treatment so often affects its progress. In anaplastic carcinoma of the thyroid the effects of treatment, by surgery or irradiation, were disappointingly unsuccessful in altering the course of the disease. These tumours grew rapidly and invaded near-by structures at an early stage so that complete surgical removal was impossible. Table $\mathrm{V}$ indicates the fate of patients in this series with anaplastic carcinoma. Two of the 45 died from an unrelated disease, 41 died within two years of first attending hospital; in the majority death was due to local invasion by the tumour before any obvious metastases developed. There are only six survivors, the longest survival time being six years, and the overall impression is one of rapid and relentless progress.

Seven patients with differentiated carcinoma were thyrotoxic in greater or lesser degree. Of these seven patients three presented with hyperthyroidism, one had a B.M.R. of $+32 \%$, one had $+38 \%$, and one had a ${ }^{131} \mathrm{I}$ uptake at 24 hours of $80 \%$. They were all treated with antithyroid drugs, and at thyroidectomy a carcinoma was an unexpected finding. At 2, 3, and 12 years they were well, with no evidence of malignant disease or hyperthyroidism; all three lesions were welldifferentiated papillary in type. The fourth patient was treated with radiotherapy in 1937 at the age of 18 for hyperthyroidism; a partial thyroidectomy in 1955 revealed a follicular carcinoma and subsequent treatment was with ${ }^{131} \mathrm{I}$. No metastases have been detected. The fifth, a man of 52, was hyperthyroid and had fibrillation; thyroidectomy revealed a follicular lesion. The other two were described as mildly toxic clinically, but no laboratory tests are available to substantiate this, although Lugol's iodine was given prior to thyroidectomy. Only one patient in the anaplastic group was diagnosed as thyrotoxic, and this was not satisfactorily established.

\section{Factors in Management of Thyroid Carcinoma}

The main purpose of reviewing a group of patients such as these is to try to discover those factors which will aid in the prevention, diagnosis, and treatment of thyroid cancer in the future.

\section{Prophylaxis}

Many patients with differentiated carcinoma of the thyroid give a long history of a swelling in the neck. Whether such a goitre is malignant $a b$ initio or represents malignant change in a benign nodule is a matter for conjecture. Certainiy, measures designed to prevent the genesis of the thyroid nodule might well result in a decrease in the incidence of thyroid carcinoma.

Diffuse enlargement of the thyroid gland before puberty is commonly due to a deficient intake of iodine in the diet (normal intake 100-200 $\mu \mathrm{g}$. a day). Treatment consists in giving adequate iodine in the diet in physiological, not pharmacological amounts-that is, the use of iodized salt or potassium iodide $0.1 \mathrm{mg}$. a day (Taylor, 1956, 1960). Diffuse enlargement of the thyroid gland after puberty rarely diminishes when the iodine content of the diet is increased. If, however, thyroid hormone is given by mouth, T.S.H. secretion of the anterior pituitary is depressed and the goitre often disappears. It is usually necessary to give full replacement dosage for at least a year to obtain this satisfactory result. This means thyroid tablets 3 gr. $(0.2$ g.) a day, or thyroxine sodium tablets $0.3 \mathrm{mg}$. a day, or triiodothyronine tablets $80 \mu \mathrm{g}$. a day. "Diotroxin" $0.1 \mathrm{mg}$. three times a day, containing $90 \%$ thyroxine and $10 \%$ triiodothyronine (these amounts of hormones approximate to what Maclagan et al. (1957) found in the blood of a group of normal adults) is considered to offer the best treatment (Taylor, 1961).

Since there appears to be a relationship between irradiation of the neck and thorax in early life and the subsequent development of carcinoma of the thyroid (Winship and Rosvoll, 1961), every effort should be made to avoid the use of $x$ rays and radioactive iodine tests in the mother during pregnancy. Irradiation of the neck and radioiodine should also be avoided whenever possible in patients before puberty.

\section{The Single Nodule}

A solitary nodule in the thyroid gland, particularly in a child or in a young adult, should always be excised, not forgetting that nodules which appear solitary on clinical examination may prove multiple at operation. Many patients in this series with a differentiated carcinoma presented with a single nodule and no other symptom or sign. It is possible that those who died might have been saved if the condition had been diagnosed and treated earlier.

\section{Radioiodine in Diagnosis}

In the diagnosis of thyroid carcinoma radioiodine plays a rather negative part, but it has a positive contribution to make in investigative techniques such as autoradiography. All patients suspected of thyroid carcinoma, except those who are pregnant or those below 
the age of puberty, should be investigated with radioiodine ; the neck uptake at 24 and 48 hours is estimated and the plasma level of protein-bound radioactive iodine at 48 hours determined. The neck is scanned at this time, either with a mechanical scintiscanner or simply by hand, using a well-collimated scintillation tube ; this technique is most valuable in assessing solitary nodules. If activity over the nodule is greater than over the rest of the gland, the diagnosis of carcinoma can be ruled out, for neoplastic tissue is always less efficient than normal thyroid at taking up iodine. Areas in the gland which do not take up the isotope merely raise the suspicion that carcinoma is present ; many other lesions, such as haematomas, cysts, and thyroiditis, also show diminished iodine uptake. Some workers have found scanning the neck after a tracer dose of radioactive phosphorus useful, as neoplastic tissue is usually more cellular than the rest of the thyroid and so gives higher counts (Ackerman et al., 1961).

Whenever the diagnosis of thyroid carcinoma seems very likely it is convenient to give a large tracer dose of radioiodine-from 0.5 to $1 \mathrm{mC}$-administering it 48 hours before thyroidectomy. This enables a number of things to be done: (1) scanning neck and body ; (2) autoradiography of the operative specimen, using slices cut through whole lobes, and of metastases where these can be excised; and (3) samples of blood can be chromatographed to see if compound $\mathrm{X}$, the abnormal iodoprotein, is present. This substance was first described by Robbins et al. (1955), and is present in some $60 \%$ of patients with malignant thyroid disease. Finally, the presence of radioiodine in the thyroid can be a help when total thyroidectomy is being performed. After the gland has been excised a sterile needle counter is used to survey the wound area, and if any fragment of thyroid tissue has been inadvertently left behind it will easily be detected and can then be excised.

\section{Biopsy in Diagnosis}

Before adequate treatment can be instituted in any patient with suspected thyroid carcinoma a firm diagnosis must be made, and this will involve removing tissue for histological examination. Where the disease process appears diffusely, to involve a large part or most of the thyroid gland, the use of a split needle of the Vim-Silverman type (Taylor, 1955) or a high-speed drill (Deeley, 1960) has proved very satisfactory and has produced no serious complication. The amount of tissue removed is small, but it usually proves adequate for diagnostic purposes. When the lesion is a solitary nodule or is small and circumscribed, needle biopsy should not be used; it is far better to perform an excision biopsy. Crile et al. (1955) have suggested that needling a solitary nodule may lead to spread of the disease, but it would require more evidence than they present to substantiate this.

Ideally a frozen section should be examined by a pathologist skilled in thyroid histology so that, when necessary, the surgeon can proceed to total thyroidectomy. The use of one of the modern cryostats (Pearse, 1960) is helpful in providing good frozen sections, but their interpretation may be difficult, and a negative report does not necessarily exclude carcinoma.

\section{Surgery}

In the group of undifferentiated carcinomas some form of surgical excision was done in 30 of the 66 patients. We have now abandoned radical surgery for anaplastic lesions, since a full course of radiotherapy offers the best chance of prolonged survival ; indeed, the tendency to early invasion of neighbouring structures makes complete excision unlikely.

In the group of differentiated carcinomas 79 of the 86 patients underwent some form of excision procedure. There is evidence that this is a multicentric disease (Clark et al., 1959), as might be expected if the condition is initiated by or dependent on hormonal activity. That being so, it would seem logical to advise total thyroidectomy whenever the disease is diagnosed; but this is still a controversial point, especially when carcinoma is diagnosed only after the histological examination of a single removed lobe. Indeed, the results in our series would appear to favour a thyroidectomy less than total, but it must be remembered that during most of this series total thyroidectomy was used only for the more advanced lesions.

The long natural history of the differentiated carcinoma, together with the occasional good response to radioiodine and hormonal therapy of some of these tumours, enables a hopeful attitude to be adopted. Thyroidectomy remains the treatment of choice for the primary carcinoma, and certainly, while nothing less than a hemithyroidectomy is acceptable, total thyroidectomy seems to be preferable on theoretical grounds. All lymph nodes which appear to be involved are excised at the same time and the patient is regularly examined thereafter so that if further spread occurs it can be promptly treated.

\section{Isotope Therapy}

Radioiodine has now been used in the treatment of differentiated thyroid cancer for well over ten years (Dobyns and Maloof, 1951 ; Maloof et al., 1956 ; Pochin, 1957 ; Taylor and Goolden, 1959). The principle of reserving such treatment for selected patients with metastatic disease is a sound one, while the primary tumour with its immediate extensions is best treated by conventional surgical methods. In our series ${ }^{131} \mathbf{I}$ therapy was used in 30 of the 86 patients with a differentiated lesion. As expected, it was used most often in those lesions with abundant colloid, although Pochin et al. (1952) have shown that there is not always correlation between radioiodine uptake and the presence of colloid-filled follicles. Autoradiography can give more precise evidence of the suitability of a malignant lesion for radioiodine treatment when a metastasis can be partly or wholly removed for examination after a generous tracer dose of ${ }^{131} \mathrm{I}$. On one occasion a piece of rib containing a secondary deposit was removed at the same time as total thyroidectomy, and autoradiographs of the rib showed good blackening over welldifferentiated follicular carcinoma. Subsequent therapy to secondary deposits in vertebrae has produced a long remission. However, we have found autoradiography most useful three months after total thyroidectomy, for by then the metastases are more likely to show concentration of the isotope.

In assessing the place of ${ }^{131}$ I therapy, it must be remembered that irradiation alters the structure of the thyroid cells. We have therefore, on theoretical grounds, considered that the first therapeutic dose should be a maximal one compatible with safety, for the isotope may not be as effectively taken up the second time. Methods designed to increase the concentration of ${ }^{131} I$ in the 
metastases should always be considered before the therapeutic dose is administered.

Although ${ }^{131} \mathrm{I}$ tracer studies were made in patients with anaplastic carcinoma, isotope therapy had nothing to offer this group.

\section{Radiotherapy}

External irradiation, either as the sole therapy or combined with surgical excision, was used to treat 49 patients with anaplastic carcinoma of the thyroid. It was frequently used for palliation rather than cure, and it probably achieved this in many cases. There is little to suggest that a cure is likely with radiotherapy, but two patients have survived for more than five years.

External irradiation was used in the treatment of 52 patients with a differentiated carcinoma, but most of these were treated in the first five years of the study before it was realized that it makes little impression on the well-differentiated lesion, the proper treatment of which is surgical excision. Distant metastases which cannot be excised should be treated by isotope therapy. When, however, a metastasis does not take up radioiodine and is causing symptoms, as with backache from a deposit in a lumbar vertebra or haemoptysis from a secondary in the lung, local $x$-irradiation may provide palliation.

\section{Thyrotrophin Suppression}

Dunhill (1937) was the first to demonstrate that certain very well differentiated thyroid carcinomas were under the control of the anterior pituitary and that by administering thyroid by mouth the pituitary was suppressed and the carcinoma stopped growing or regressed. His first patient had been operated on twice before the age of $\mathbf{1 3}$ for thyroid cancer; Dunhill treated the third recurrence with fairly large doses of thyroid and the patient is still alive. Balme (1954) and Crile (1957) also drew attention to this endocrine dependency of certain thyroid cancers, as was done more recently by Thomas and Burns (1961).

We give all our patients with thyroid carcinoma maximum doses of thyroid hormone (diotroxin 0.3 to $0.4 \mathrm{mg}$. daily) irrespective of any other method of treatment. This dosage, which represents full replacement therapy, is intended to suppress the output of thyrotrophin and so halt or slow down the progress of the disease or prevent its recurrence.

\section{Summary}

A study of 152 patients with thyroid carcinoma highlights the fundamental difference which exists between differentiated and anaplastic carcinoma of the thyroid gland. It is possible that the aetiology of the two conditions is entirely different, the differentiated being a hormonally dependent tumour occurring in the young thyroid, the anaplastic an inexplicable malignant change occurring in the older gland. In differentiated carcinoma there are means available for controlling the disease and arresting or reversing the malignant process. Anaplastic carcinoma presents the same problems as cancer elsewhere in the body, the locality giving this particular tumour a worse prognosis than most.

We are indebted to our colleagues at both hospitals, especially the members of the departments of physics, radiotherapy, and pathology.
REFERENCES

Ackerman, N. B., Shahon, D. B., and Harvin, J. F. (1961). In Advances in Thyroid Research, edited by $\mathrm{R}$. Pitt-Rivers, p. 368. Pergamon Press, London.

Alhadeft, R., Scott, F., and Taylor, S. (1956). Brit. J. Surg., 43, 617 .

Balme, H. W. (1954), Lancet, 1, 812.

Bielschowsky, F. (1944). Brit. J. exp. Path., 25, 90.

Brewer, D. B., and Orr, J. W. (1953). J. Path. Bact., 65, 193.

C.ark, R. L., White, E. C., and Russell, W. O. (1959). Ann. Surg., 149, 858 .

Crile, G., jun. (1957). Cancer, 10, 1119.

Crile, G., jun. (1957). Cancer, 10, 1119.

- and Hazard, J. B. (1953). Ann. Surg., 138, 33. Suhrer, J. G., jun., and Hazard, J. B. (1955). Ibid., 15, 1422.

Deeley, T. J. (1960). Acta Un. int. Cancr., 16, 338.

Dobyns, B. M., and Maloof, F. (1951). J." clin. Endocr., 11, 1323.

Doniach, i. (1957). Brit. J. Cancer, 11, 67.

- (1958). Brit. med. Bull., 14, 181.

Dunhill, T. P. (1931). Brit. J. Surg., 19, 83.

(1937). Trans. med. Soc. Lond., 60, 234

rantz, U. K., and Yannopoulos, $\mathbf{K}$. (1961). In Advances in Thyroid Research, edited by R. Pitt-Rivers, p. 377. Pergamon Press, London.

Kilpatrick, R., Blomfield, G. W., Neal, F. E., and Wilson, G. M. (1957). Quart. J. Med., 26, 209.

Lindsay, S. (1960). Carcinoma of the Thyroid Gland. Thomas, Illinois.

Maclagan, N. F., Bowden, C. H., and Wilkinson, J. H. (1957). Biochem. J., 67, 5. Maloof, F., Vickery, A. L., and Rapp, B. (1956). J. clin.

Money, W. L., and Rawson, R. W. (1950). Cancer, 3, 321.

Pearse, A. G. E. (1960). Histochemistry: Theoretical and Applied, 2nd ed., p. 13. Churchill, London."

Pemberton, J. de J. (1938). Trans. Amer. Ass. Goiter, p. 154.

Pochin, E. E. (1957). Postgrad. med. J., 33, 317. Hilton, G., Myant, N. B., Honour, A. J., and Corbett, B. D. (1952), Brit. med. J., 2, 1115.

Robbins, J., Rall, J. E., and Rawson, R. W. (1955). J. clin. Endocr., 15, 13i5.

Simpson, C. L., and Hempelmann, L. H. (1957). Cancer, 10, 42.

Sokal, J. E. (1953). New Engl. J. Med., 249, 393.

Taylor, S. (1955). British Surgical Practice. Surgical Progress, p. 148. Butterworth, London (1956). Amer. J. Med., 20, 698. (1960). Brit. med. Bull., 16, 102 (1961). Lancet, 1, 341.

and Goolden, A. W. G. (1959). In Treatment of Cancer in Clinical Practice, edited by P. B. Kunkler and A. J. H. Rains, p. 410. Livingstone, Edinburgh.

Thomas, C. 'G., and Burns, S. D. (1961). In Advances in Thyroid Research, edited by R. Pitt-Rivers, p. 361. Pergamon Press, London.

Vanderlaan, W. P. (1947). New Engl. J. Med., 237, 221.

Walthard, B. (1961). In Advances in Thyroid Research, edited by R. Pitt-Rivers, p. 350 . Pergamon Press, London.

Warren, S., and Meissner, W. A. (1953). Atlas of Tumor Pathology, Sect. IV, Fasc. 14. Armed Forces Institute of Pathology, Washington, D.C

Wegelin, C. (1928). Cancer Rev., 3, 297

Willis, J. (1961), Brit. med. J., i, 1646.

Wilson, L. B. (1921). Ann. Surg., 74, 129

Winship, T., and Rosvoll, R. V. (1961). In Advances in Thyroid Research, edited by R. Pitt-Rivers, p. 358. Pergamon Press, London.

Woolner, L. B., Beahrs, O. H., Black, B. M., and McConahey, W. M. (1960). Excerpta Medica, Int. Congress Series. The Fourth International Goitre Conference, No. 26, p. 52.

Wynder, E. L. (1952). New Engl. J. Med., 246, 573.

Speaking at a conference of directors in Glasgow organized by the Scottish Industrial Groups' Advisory Council, the Minister of Labour, Mr. John Hare, said that figures published in the annual report of the Chief Inspector of Factories showed that the number of accidents in Scotland was somewhat higher than the general average. They had been increasing in recent years, and a particularly powerful effort was therefore needed to arrest and reverse these trends. At present, he pointed out, the chances were that one in every 300 men working in a factory would be killed at work, and that each one during his working life would have at least one accident, serious enough to keep him away from work. In the more dangerous jobs, such as construction or shipbuilding, the chances of being killed were one in 100, and two or three to one of being injured. The average cost of a "lost-time" accident had been put at $£ 300$, and that of a minor one at between $£ 10$ and $£ 20$. 